\title{
Uma revisão sobre os problemas emocionais e as orientações e intervenções em saúde mental na assistência pré-natal
}

\author{
Márcia Rosana Forster Wazlawik*, Fernanda Sarturi**
}

RESUMO: Os aspectos emocionais podem interferir no pré-natal e também refletir na relação mãe/bebê. Este estudo vem identificar na literatura, problemas de ordem emocional no pré-natal, as intervenções e as orientações voltadas à saúde mental e quais os profissionais que se envolvem com estas questões. Foi consultada a base de dados SCIELO no período entre 2005 a 2010. Como resultados destacam-se estudos que investigam problemas como depressão, baixa autoestima, ansiedade e uso de tabaco e álcool. Observou-se uma falta de padronização na assistência aos aspectos de ordem emocional à gestante e uma escassez de orientações relacionadas aos aspectos psíquicos que influenciarão 0 desenvolvimento do bebê. Os profissionais envolvidos nas orientações são na maioria da área médica e de enfermagem. Entende-se que as políticas de saúde da mulher, especificamente no pré-natal, deveriam ser aprimoradas, dando maior relevância aos aspectos de saúde mental das gestantes, capazes de propiciar qualidade nos aspectos emocionais.

Descritores: Gestantes, Cuidado pré-natal, Problemas emocionais, Saúde mental.

\section{A review of emotional problems and the guidelines and mental health interventions in prenatal care}

ABSTRACT: The emotional aspects can interfere with prenatal and also reflect on the mother/baby relationship. This study has identified in the literature, problems of emotional prenatal, interventions and guidelines aimed at mental health and what the professionals involved with these issues. For this it was used the SciELO database, in the period between 2005 and 2010. As results, stand studies investigating problems, as depression, anxiety, alcohol use and low self-esteem. It was also observed a the lack of standardization on the emotional aspects with the treatment of the pregnant. The professionals that are involved with the orientations are mostly of the medical and nursing areas. It is understood that women's health policies, specifically in the prenatal, should be improved, giving more relevance to the aspects of the pregnant mental health, capable to provide quality on the emotional aspects.

Descriptors: Pregnant, Prenatal care, Emotional problems, Mental health. 
O acompanhamento pré-natal de reconhecido efeito positivo sobre a saúde materna e também em relação à saúde do bebê já é amplamente conhecido, mas necessita ainda um maior aperfeiçoamento, de forma a garantir a diminuição de óbitos em crianças menores de cinco anos, melhorar os cuidados à gestante e ao recém-nascido, além de identificar distúrbios que possam interferir no desenvolvimento infantil.

Sabe-se também que durante a gestação, onde ocorrem várias mudanças físicas, hormonais e psicológicas, podem advir transtornos psíquicos, ocasionando danos não só à saúde materna, mas comprometer a qualidade da relação mãe-criança e também 0 desenvolvimento do bebê.

Além de que, a assistência em geral na forma como é prestada atualmente, ainda está centrada no uso de tecnologias duras, como exames e medicamentos desconexos de uma assistência articulada e cuidadora ${ }^{1}$, não propiciando a integralidade de atenção à saúde, $\mathrm{e}$ muitas vezes valorizando em demasia apenas a parte biológica.

Importante destacar que foram implementadas diversas políticas de saúde na área materno-infantil ao longo dos anos e que estas tiveram um papel fundamental na melhoria de indicadores². 0 autor do trabalho "Políticas de Saúde Materna no Brasil: os nexos com indicadores de saúde materno-infantil", ainda refere que o Programa de Humanização do Pré-natal (PHPN), como instrumento de gestão, procura executar as medidas essenciais visando a promoção da saúde materno-infantil. Entretanto, a assistência ainda requer um trabalho mais efetivo, sendo fundamental repensar a execução de políticas públicas para a melhoria da qualidade da atenção à saúde da mulher. Além disso, pressupõe que para ter qualidade no pré-natal não basta apenas determinar uma quantidade maior de consultas, e sim, o estabelecimento de critérios bem definidos nesta assistência.

Como assistência em saúde mental no pré-natal, entende-se aqui, as ações prestadas pelos profissionais da saúde, relacionadas à avaliação, à escuta e a orientações preventivas e terapêuticas, voltadas a saúde psíquica da mãe e também, orientações que influenciarão a saúde psíquica do bebê, além do suporte emocional oferecido à gestante. Em suma, as questões que permeiam esta pesquisa são: quais as orientações prestadas e técnicas utilizadas, e que profissionais de saúde se envolvem nestas orientações?

Neste contexto, o interesse em estudar a assistência psíquica no pré-natal, surgiu a partir da vivência profissional na coordenação municipal do Programa Primeira Infância Melhor (PIM), da Secretaria de Saúde do município de Santa Cruz do Sul - RS, o qual promove 0 acompanhamento a gestantes e também a famílias com crianças de zero a seis anos de idade, visando o seu desenvolvimento integral. E, também, porque no decorrer da experiência profissional, vem tornando-se necessário repensar a assistência, aprofundando a discussão sobre os fundamentos teóricos, incluindo de forma efetiva na atenção ao pré-natal, a dimensão psíquica e os fatores que afetam e influenciam o desenvolvimento maternoinfantil.

Assim, o objetivo desta revisão é investigar na literatura brasileira, a ocorrência de problemas de ordem emocional relacionados às gestantes, as orientações e intervenções em saúde mental reportados nos estudos analisados, além de identificar quais são os profissionais responsáveis pelas intervenções.

Saúde (Santa Maria), Ahead of print, n.1, p. 31-46, orientaçōes e intervenções em saúde mental na assistência pré-natal ISSN 2236-5834 
Este trabalho tem o fim de proporcionar subsídios para proposição de ações específicas no cuidado à saúde materna que envolva a parte psicológica e que, de certa forma, poderia melhorar os indicadores, pois, sabe-se também que famílias onde as crianças são amadas e desejadas por seus pais desde a gestação, acabam contribuindo na redução de maus tratos na infância, bem como 0 uso abusivo de drogas na adolescência e consequentemente a diminuição da violência através de ações preventivas.

\section{Metodologia}

O presente trabalho trata-se de uma pesquisa bibliográfica descritiva, realizada no banco de dados Scientific Electronic Library Online (SCIELO), utilizando as palavras chave: gestantes, cuidado pré-natal, problemas emocionais e saúde mental. Foi consultado em maio de 2012, o período entre 2005 a 2010.

A pesquisa dividiu-se em três momentos: primeiramente realizou-se a busca dos resumos pelas palavras chave, pertinentes ao período de janeiro de 2005 a dezembro de 2010 e contabilizados; em um segundo momento foi escolhido resumos que contemplavam orientações, educação ou avaliação da atenção no pré-natal, ou ainda, resumos com intervenções em saúde mental ou aqueles relacionados a problemas emocionais. E em um terceiro momento, eliminaram-se os estudos, que não abordavam a saúde mental ou os que não incluíam a importância de cuidados psicológicos na gestação

Para análise dos resultados seguiu-se as recomendações que definem a sistematização do conteúdo em categorias ${ }^{3}$ e que foram descritas a seguir.

\section{Resultados}

Em virtude de não ter encontrado nenhum resultado para as palavras chave de forma agrupada, a pesquisa deu-se com as palavras chave de forma isolada, totalizando 1119 artigos. O Quadro 1 traz os resultados do primeiro momento da pesquisa..

\begin{tabular}{|c|c|}
\hline Palavras-chaves & Total por assuntos \\
\hline Gestantes & 582 \\
\hline Cuidado pré-natal & 108 \\
\hline Saúde mental & 383 \\
\hline Problemas emocionais & 46 \\
\hline Total & 1119 \\
\hline
\end{tabular}

Quadro 1 - Resumos disponíveis sobre gestantes; cuidado pré-natal, problemas emocionais e saúde mental no período de janeiro de 2005 a dezembro de 2010 - Scielo. 
A partir deste momento, deu-se início ao segundo momento da pesquisa, ou seja, selecionados os resumos que indicassem orientações, educação ou avaliação da atenção no pré-natal de baixo risco, ou ainda, resumos com intervenções em saúde mental ou relacionados a problemas emocionais na gestação. Foram selecionadas 166 ocorrências distribuídas no Quadro 2.

\begin{tabular}{|c|c|}
\hline Palavras-chaves & Total por assuntos \\
\hline Gestantes & 101 \\
\hline Problemas emocionais & 05 \\
\hline Cuidado pré-natal & 51 \\
\hline Saúde mental & 9 \\
\hline Total & 166 \\
\hline
\end{tabular}

Quadro 2 - Resumos envolvendo assistência pré-natal de baixo risco, educação em saúde, orientações, intervenções ou avaliação em saúde mental no pré-natal ou ainda, relacionados a problemas emocionais - Scielo.

Após a leitura dos 166 resumos, iniciou-se o terceiro momento da pesquisa, eliminandose os estudos que não abordavam a saúde mental ou os que não incluíam a importância de cuidados psicológicos, e que está demonstrado no Quadro 3.

\begin{tabular}{|c||c|c|c|c|c|c|c|}
\hline $\begin{array}{c}\text { Ano } \\
\text { Palavras-chaves }\end{array}$ & 2005 & 2006 & 2007 & 2008 & 2009 & 2010 & $\begin{array}{c}\text { Total por } \\
\text { assuntos }\end{array}$ \\
\hline Gestantes & 05 & 04 & 07 & 04 & 06 & 09 & 35 \\
\hline $\begin{array}{c}\text { Problemas } \\
\text { emocionais }\end{array}$ & 02 & - & 01 & - & - & - & 03 \\
\hline Cuidado pré-natal & 01 & 01 & 02 & - & 01 & 03 & 08 \\
\hline Saúde mental & 01 & - & 01 & - & 01 & - & 03 \\
\hline Total por período & 09 & 05 & 11 & 04 & 04 & 12 & 49 \\
\hline
\end{tabular}

Quadro 3 - artigos que abordavam a saúde mental ou ainda os que incluíam importância dos cuidados psicológicos no prénatal - Scielo.

O universo da pesquisa foi constituído por 49 artigos na base de dados Scielo. Entre estes estudos, 9 estavam em duplicidade, totalizando 40 artigos.

\section{Discussão}

Realizada a leitura do material, verificou-se que vários estudos relatam a importância da atenção aos aspectos psíquicos/emocionais durante a gestação. Mas ao mesmo tempo, se

Saúde (Santa Maria), Ahead of print, n.1, p. 31-46, ma revis̃o sobre os problents emocionais e as orientaçöes e intervençōes em saúde mental na assistência pré-natal compararmos ao número total de artigos que abordam os aspectos físicos e biológicos no pré-natal, em relação às palavras chave pesquisadas, verifica-se um percentual de $4,38 \%$ do total de artigos publicados nesta biblioteca. 
O quadro 4, apresenta os estudos que abordam a saúde mental no pré-natal ou que discutem a importância dos cuidados psicológicos em comparação ao número de estudos contendo a palavra chave.

\begin{tabular}{|c|c|c|}
\hline Palavras-chaves & $\begin{array}{c}\text { Número de estudos que } \\
\text { abordam saúde mental ou a } \\
\text { importância de cuidados } \\
\text { psicológicos no pré-natal }\end{array}$ & $\begin{array}{c}\text { Número de estudos contendo } \\
\text { a palavra chave }\end{array}$ \\
\hline Gestantes & 35 & 108 \\
\hline Cuidado pré-natal & 08 & 383 \\
\hline Saúde mental & 03 & 46 \\
\hline Problemas emocionais & 03 & 1119 \\
\hline Total & 49 &
\end{tabular}

Quadro 4 - Número de estudos que abordam a saúde mental ou a importância dos cuidados psicológicos no pré-natal em relação às palavras chave pesquisadas - Scielo.

Em relação à palavra chave gestante, esta, apresentou 582 ocorrências na base de dados Scielo e o número de estudos relacionados a ela que envolvem a saúde mental no prénatal é de 35 ocorrências, significando $6,01 \%$ dos estudos. Cuidado pré-natal revela um percentual de $7,40 \%$.

Assim, é importante refletir sobre a proporção de artigos que abordam a saúde mental das gestantes e/ou discutem a importância dos cuidados psicológicos no pré-natal em relação aos estudos que abordam os aspectos físicos e biológicos. De um total de 1119 artigos, apenas 49 incluíram aspectos de saúde mental ou que referenciaram a importância de cuidados psicológicos e entre estes, nove ainda estavam em duplicidade.

Este fato indica a necessidade de mais estudos que abordem esta questão, visando entre outras coisas, mais qualidade na atenção à saúde da mulher e consequentemente da criança.

Em relação aos conteúdos identificados nos estudos, procuramos sistematizá-los, organizando as informações obtidas na leitura em duas categorias. São elas: estudos que evidenciam problemas de ordem emocional em gestantes e estudos que abordam as intervenções relacionadas à saúde mental da gestante e/ou orientações que influenciarão na saúde psíquica do bebê.

\section{Estudos que evidenciam problemas de ordem emocional em gestantes}

Em relação à saúde mental da gestante, ao avaliar a prevalência de transtornos mentais comuns (TMC) e sua relação com autoestima, num estudo com gestantes atendidas pelo serviço público na cidade de Pelotas/RS ${ }^{4}$, verificou a alta prevalência de TMC nessa amostra e sua significativa associação com menor autoestima. Os dados mostram que a escolaridade, a condição socioeconômica e o pouco suporte familiar estão relacionados à maior probabilidade da gestante apresentar o transtorno. Na pesquisa, foi evidenciado ainda, o fato de que essa interação entre TMC e menor autoestima na gestação pode levar a um prejuízo no desenvolvimento do bebê.

Saúde (Santa Maria), v.38, n.1, p. 31-46, 2012. Wazlawik, M. R. F.; Sarturi, F. 
Em outra pesquisa que avaliou a autoestima de 127 gestantes durante o pré-natal no sistema público de saúde, através da aplicação da Escala de Autoestima de Rosemberg, verificou que $60 \%$ das gestantes avaliadas apresentaram autoestima insatisfatória ${ }^{5}$. Entre as gestantes que referiram gestação não planejada, foi maior a prevalência de autoestima insatisfatória do que aquelas que referiram tê-la planejado. Além disso, a ausência de apoio do parceiro para cuidar do filho após seu nascimento também esteve associada a menor autoestima nas grávidas.

Já em outro estudo ${ }^{6}$, com 560 gestantes, comparando a autoestima entre gestantes que tinham o diagnóstico de alto e baixo risco na gestação, encontrou resultados inovadores sobre a autoestima em gestantes, pois ao contrário do que se pensava nesse estudo, as gestantes de alto risco não apresentaram pior autoestima quando comparadas a gestantes de baixo risco. Supondo-se assim, que a pessoa ao ser mais cuidada por um diagnóstico de alto risco e por receber mais apoio e também maior atenção da família, poderia resultar em melhora na autoestima. Refere também que encontrou associação de menor autoestima com o número de gestações. Na medida em que há o aumento do número de gestações, diminui a autoestima.

Estas pesquisas indicam a relevância e a necessidade de mais investigações, pois problemas relacionados à autoestima podem interferir negativamente, comprometendo a relação mãe/bebe, e ao mesmo tempo evidenciam a importância do cuidado e da atenção aos aspectos emocionais no pré-natal.

Outra análise, envolvendo adolescentes grávidas ${ }^{7}$, cujo objetivo foi avaliar a depressão durante a gestação e quais os fatores associados em adolescentes atendidas numa unidade básica de saúde no município do Rio de Janeiro entre agosto de 2006 e julho de 2007. Os resultados verificados demonstram uma em cada sete gestantes com diagnóstico de depressão, o que corresponde a uma prevalência de 14,2\%. Aponta ainda, ser este um transtorno mental comum entre esta população e, inclusive, sugerindo a necessidade de incluir na rotina de atendimento pré-natal a investigação sobre depressão de adolescentes grávidas.

Ainda em relação a gestantes adolescentes, em outro estudo ${ }^{8}$, cujo objetivo foi estimar a prevalência de problemas de saúde mental em adolescentes primigestas e comparar o perfil de saúde mental com gestantes sexualmente ativas que nunca engravidaram, registrou não haver diferença quanto à prevalência do total de problemas de saúde mental em relação a grávidas e não grávidas adolescentes. Mas conclui que foi maior a frequência de sintomas de ansiedade e depressão e também maior uso de tabaco no grupo das primigestas.

Com as informações deste estudo, corrobora-se para cuidados mais adequados às necessidades das gestantes e a importância da atenção no pré-natal também ser voltada a saúde mental das gestantes adolescentes.

No tocante a ansiedade, uma pesquisa realizou uma análise transversal com 151 gestantes e verificou uma elevada prevalência de ansiedade (64,9\%). ${ }^{9} \mathrm{O}$ estudo ainda relatou, ser este risco $35 \%$ maior para ansiedade em gestantes mais jovens e também apontando um risco maior de $40 \%$ para gestantes com menor escolaridade. 0 estudo revela ainda que esta alta prevalência pode ser parcial devido a dificuldades na avaliação, uma vez que os sintomas de ansiedade podem ser associados a sintomas de depressão. E também pelo ponto de corte utilizado para a avaliação, o que poderia apresentar falsos positivos, superestimando a avaliação. Mas, ao mesmo tempo, evidencia-se pelo estudo, a importância de programas preventivos em saúde mental na atenção primária, e na atenção secundária, 0 estímulo ao acompanhamento com o devido suporte à gestante. 
Ao avaliar $^{10}$ a prevalência de sintomas depressivos no pós-parto, a partir de nove semanas do nascimento do bebê até os quatro meses foi verificado que na amostra pesquisada, houve uma prevalência de depressão de $28 \%$, dado este, superior à média mundial. Neste estudo, a sintomatologia depressiva não interferiu na qualidade da relação mãe-criança. Entretanto, o autor cogita que aspectos mais sutis, porém importantes da interação, possam não ter sido avaliados, sendo interessante incluir outras dimensões na avaliação. Outro fator que poderia ter influenciado nos resultados foi a alta taxa de perda, pois entre as desistentes poderiam estar as mães como menor disponibilidade emocional. 0 estudo ainda ressalta a importância do apoio social recebido pela mãe, pois além de funcionar como proteção para sintomas depressivos, apresenta correlação positiva com a estruturação materna e com a responsividade do bebê. Os resultados deste estudo destacam que a gestação e o puerpério devam ser considerados como momentos críticos para 0 desenvolvimento infantil e por isso deva ser dado uma atenção especial a este momento pelos gestores responsáveis das políticas de saúde.

Em outra pesquisa ${ }^{11}$, ao estudar as relações existentes entre 0 tipo de vinculação da gestante, sintomas de ansiedade, depressão e nível de apego materno fetal indicou que existe associação significativa entre o tipo de vinculação da gestante e 0 apego materno fetal e sintomas depressivos. As gestantes que apresentaram pouca ansiedade e poucos sintomas depressivos estavam no grupo de gestantes que possuíam uma vinculação segura e demonstravam apego materno fetal alto.

Os problemas de ordem emocional na gestação e puerpério são reconhecidos por vários autores, inclusive alertando para a necessidade de se incluir de forma rotineira, investigações sobre a saúde mental das gestantes. Sob este prisma, vale destacar a necessidade de haver um acompanhamento maior nas questões que envolvam os aspectos emocionais durante a assistência pré-natal.

Da mesma forma, estudos que envolveram o uso abusivo de álcool, também refletem problemas de ordem emocional ou relacionados a desordens psíquicas.

Ao investigar a relação entre consumo de álcool e problemas emocionais em gestantes foi constatado que gestantes com consumo nocivo de álcool tiveram mais problemas emocionais quando comparado àquelas cujo consumo não era problemático ${ }^{12}$. Nesse estudo, onde foram avaliadas 450 gestantes, encontraram 172 gestantes $(38,2 \%)$, problemáticas. Dentre estas, 41 (9,1\%) com consumo problemático de álcool, 27 (6,0\%) com diagnóstico de uso nocivo e $14(3,1 \%)$, dependentes do álcool. Mostrou ainda que o uso nocivo ou síndrome de dependência ao álcool relacionou-se à maior intensidade de sofrimento emocional das gestantes, apontando a necessidade de uma avaliação mais detalhada no pré-natal devido aos riscos à saúde materno-infantil.

Em estudo com 537 gestantes em 200013, 40\% relataram o uso de álcool durante a gravidez, concluindo a alta prevalência de uso inadequado de álcool. Além disso, enfatiza-se que 0 álcool é um sério problema de saúde pública. Outra pesquisa ${ }^{14}$, ressalta a importância da atenção à saúde mental de gestantes, pois os resultados verificados sugerem um número elevado de gestantes com transtornos psíquicos e que fazem uso de álcool. Foram entrevistadas 260 gestantes, onde 64 foram consideradas com consumo alcoólico de risco.

O hábito de consumir bebida alcoólica de forma moderada foi verificado em $10 \%$ das gestantes estudadas ${ }^{15}$. Ao mesmo tempo verificou que estas o faziam por se sentirem felizes e/ou descontraídas em atividades festivas, diferenciando das mulheres que o fazem de forma

Saúde (Santa Maria), v.38, n.1, p. 31-46, 2012. Wazlawik, M. R. F.; Sarturi, F. ISSN $2236-5843$ 
crônica, por este uso estar mais associado ao diagnóstico de depressão. Mas como mostra esta pesquisa, a literatura científica indica abstinência integral de álcool, não preconizando 0 seu uso em nenhum momento.

Já na investigação sobre 0 uso de cigarro e álcool na gestação ${ }^{16}$, foi encontrado que $7,4 \%$ das puérperas relataram ao médico o uso de álcool durante a gestação, concluindo que deve ser investigada esta questão, principalmente nas gestantes que não tem o companheiro, com aborto prévio, acima dos 35 anos e as que relatam gravidez não planejada.

A preocupação com o uso abusivo de álcool durante a gestação também aponta para a relação com problemas emocionais. Neste sentido, evidencia a necessidade dos profissionais de saúde estar atentos não só aos aspectos físicos, mas aos aspectos psíquicos nos atendimentos de pré-natal, sugerindo inclusive, avaliações de rotina.

Assim, vemos que os problemas emocionais abordados nos artigos estudados são relacionados a problemas de autoestima, depressão, ansiedade e problemas com álcool e tabaco. Procuramos demonstrar no quadro 5 a quantidade de artigos evidenciados sobre estes aspectos, de acordo com 0 ano de publicação.

\begin{tabular}{|c||c|c|c|c|c|c|c|}
\hline $\begin{array}{c}\text { Ano } \\
\text { Problemas } \\
\text { emocionais }\end{array}$ & 2005 & 2006 & 2007 & 2008 & 2009 & 2010 & Total \\
\hline $\begin{array}{c}\text { Relacionados a } \\
\text { autoestima }\end{array}$ & - & - & - & 01 & 01 & 02 & 04 \\
\hline $\begin{array}{c}\text { Relacionados à } \\
\text { depressão e } \\
\text { Ansiedade }\end{array}$ & 01 & - & 02 & 01 & 03 & - & 07 \\
\hline $\begin{array}{c}\text { Problemas de álcool } \\
\text { e tabaco }\end{array}$ & 01 & - & 02 & - & 01 & 03 & 07 \\
\hline Total & 02 & - & 04 & 02 & 05 & 05 & 18 \\
\hline
\end{tabular}

Quadro 5 - Estudos relacionados às palavras chave que abordam problemas emocionais em relação aos anos pesquisados Scielo.

O quadro 5 demonstra o número de estudos que destacam os problemas de ordem emocional que acometem as gestantes, encontrados na biblioteca Scielo, através das palavras chave, em relação ao ano pesquisado. 0 total encontrado Foram encontrados são 18 artigos que evidenciam problemas emocionais no pré-natal, significando um percentual de $45 \%$ em relação ao total de artigos (40), que abordam a saúde mental e/ou a importância de cuidados psicológicos.

Nesta incursão pelos estudos, outro autor ${ }^{17}$, refere ainda que mães, em algumas situações, podem estar tão fragilizadas ou emocionalmente imaturas que precisam de atenção especial. Exposto isso, faz-se necessário suporte psíquico por parte de profissionais capacitados na gestação e pós-parto, possibilitando esta atenção sem julgamentos e sem desvalorização das situações, o que pode ser crucial à saúde mental da mãe e consequentemente de seu bebê. 
Em um estudo com objetivo de investigar as representações sociais das gestantes sobre a gestação e a atenção dispensada na consulta de enfermagem no pré-natal, refere que a descoberta da gravidez gera sentimentos como alegria, surpresa e às vezes medo e que 0 fato de ter sido planejada ou não, irão influenciar a intensidade dessas sensações ${ }^{18}$. Ainda neste trabalho, é reforçado que a consulta de enfermagem possibilita ao mesmo tempo, a expressão e a compreensão destes sentimentos e também é reconhecida como uma dimensão que possibilita o acolhimento.

Mas em relação aos cuidados com o bebê, as gestantes entrevistadas neste estudo referem que as consultas priorizam os cuidados biológicos, principalmente aqueles que envolvem o processo saúde-doença. Evidencia-se também que a mãe precisa aprender sobre as necessidades psicológicas do bebê além das necessidades fisiológicas e que a consulta de enfermagem contribui na aquisição destes conhecimentos, através do acolhimento e da escuta.

Outro estudo ${ }^{19: 281}$, reitera que "alguns conhecimentos devem ser repassados no prénatal, e assim prepará-la para receber seu filho, principalmente do ponto de vista físico e mental". Foi constatado que dez gestantes $(33,3 \%)$ tiveram participação nas atividades de grupo de orientações, e ao observar os temas abordados, uma gestante recebeu informações sobre aspectos psicológicos e sobre depressão pós-parto e duas gestantes participaram de grupo, cujas informações eram sobre medos e mitos. Em relação ao desenvolvimento do bebê, $40 \%$ referiram orientações, mas o estudo não especifica se as informações referiam-se a parte física ou psíquica. A maioria recebeu informações de médicos e enfermeiros.

Já, ao pesquisar as orientações captadas por gestantes adolescentes ${ }^{20}$, foi encontrada uma escassez de orientações sobre o cuidado com o bebê, além da falta de interesse destas gestantes em participar de grupos educativos. De 30 gestantes entrevistadas, 28 relataram não participar de cursos ou palestras. Na revisão feita por este autor, o adolescente não está preparado psiquicamente e nem fisicamente, e que "o cuidado materno constitui um conjunto de ações biológicas, psicossociais e ambientais que permitem à criança desenvolver-se bem"20:369. Mas ao mesmo tempo, a maioria das orientações referidas pelas entrevistadas, refere-se apenas a parte biológica, como higiene, alimentação, vacinação, entre outros.

É oportuno destacar a importância dos encontros grupais durante o pré-natal, mas ao mesmo tempo evidencia-se a pouca participação das gestantes nestas atividades grupais.

Outro estudo ressalta que a gravidez promove alterações físicas e emocionais, necessitando por isso de uma atenção para além do biológico ${ }^{21}$. 0 enfermeiro que atua no Programa Estratégia Saúde da Família (ESF), realiza atividades de grupo como uma continuidade da consulta de enfermagem no pré-natal e aborda além das orientações sobre a saúde física, aspectos relacionados a alterações emocionais e orientações sobre os cuidados com o bebê. Para este autor, a gestante pode vir com medos, angústias, dúvidas ou fantasias e o enfermeiro deve possibilitar esta escuta. $O$ enfermeiro também realiza encaminhamentos para outros profissionais quando necessário.

Da mesma forma, conforme os profissionais e as gestantes entrevistadas num estudo que procurou compreender os significados do cuidado humanizado no pré-natal, a atenção deveria incluir ações educativas e visitas domiciliares além do acompanhamento emocional e

Saúde (Santa Maria), v.38, n.1, p. 31-46, 2012. Wazlawik, M. R. F.; Sarturi, F.

ISSN 2236-5843 
psicológico, indo além da consulta médica e de enfermagem ${ }^{22}$. A avaliação do bem estar materno-fetal e a possibilidade de expressar sentimentos e dúvidas estão entre os cuidados que deveriam iniciar precocemente no pré-natal.

Além disso, dentre os cuidados relacionados a uma atenção integral, o estudo mostra a importância de ser trabalhado o preparo para a maternidade e paternidade, o envolvimento das relações familiares e conjugais, entre outros aspectos voltados à saúde de forma mais geral.

Em pesquisa que buscou identificar os desconfortos emocionais e físicos relatado por gestantes participantes de um grupo realizado por enfermeiros e descrever a forma utilizada para aliviar os incômodos ${ }^{23}$, os autores dizem que a abordagem com o corpo proporciona 0 surgimento de conteúdos emocionais e somáticos e alerta que estes profissionais devem estar devidamente habilitados para este cuidado e que "os recursos de abordagem corporal promoveram alívio às sensações dolorosas, ao cansaço e estresse proporcionados pelas alterações físicas e psicológicas da gravidez" 24:312. A abordagem corporal promove ainda 0 autocuidado e também serve como incentivo a uma maior participação das gestantes nos grupos.

Nesta abordagem, a cada encontro iniciava-se com o tema estabelecido anteriormente pelas gestantes e depois acontecia um momento de trabalho corporal. As técnicas utilizadas incluíam massagens, com o objetivo de reduzir as dores e também para aumentar a consciência corporal; técnicas de relaxamento para aliviar a fadiga corporal e prevenir insônia; além de outras técnicas como balanceio pélvico, técnica de contração de todos os segmentos corporais, com destaque para a contração da musculatura pélvica; técnicas de respiração torácica e abdominal, para conhecer e adotar a melhor forma de respiração durante o trabalho de parto; além de massagens para bebês, visando conforto e proteção.

Percebe-se que são valorizadas as questões emocionais e as abordagens desenvolvidas estimulam 0 acolhimento e a escuta dos sentimentos, bem como 0 alívio de sensações dolorosas. Evidencia-se também a necessidade de contemplar nos atendimentos realizados durante o pré-natal uma escuta direcionada acerca das fantasias e/ou expectativas desses pais, bem como orientações sobre a reconfiguração deste cenário familiar, incluindo as relações que se estabelecem entre a criança e as pessoas que a cercam.

Entende-se também a necessidade de destacar nos atendimentos de pré-natal, a importância da função paterna para que os pais possam ficar por dentro do processo de estruturação psíquica do bebê, discutir assuntos como inclusão do recém-chegado, preparação dos irmãos para a inclusão daquele que está por vir, limites amorosos, desmame, entre outros e, que são de extrema importância e que influenciarão o desenvolvimento psíquico do bebê. Portanto, são informações necessárias no momento da chegada de um novo ser.

Ainda em relação aos fatores que influenciarão o desenvolvimento psíquico do bebê, em um estudo com objetivo de investigar os sentimentos das gestantes sobre a maternidade ${ }^{25}$, refere que na gravidez ocorrem entre outras mudanças alterações psicológicas, tanto individuais como relacionais e que estas repercutem na relação mãe-bebê. Estas transformações, que vão permeando a relação desde a gestação, irão constituir-se no espaço psíquico do bebê muito antes desta criança nascer. Esta compreensão é necessária, revelando a importância de promover a saúde não só da gestante, mas também desta relação mãe-bebê durante a gestação. 
Em outro estudo ${ }^{26}$, aponta que, ao averiguar a constituição de um bebê imaginado durante a gestação e seus efeitos na futura relação desta mãe com seu bebê, foi identificado que a constituição de um bebê imaginado durante a gestação permite que a mãe proporcione um lugar quando este bebê na realidade chegar ${ }^{26}$. Entretanto, a investigação salienta a necessidade de deixar espaço nesta imaginação para reestruturações, uma vez que o bebê passará a existir como um sujeito diferenciado daquele que ela imaginou.

Neste sentido, outro estudo ${ }^{27}$, demonstra que a ultra-sonografia possibilita à gestante, uma visualização antes do nascimento, servindo como estímulo para imaginar mais sobre 0 seu bebê. Ademais, em outra revisão feita por este autor, fica evidenciado a importância do exame para a gestante e para a relação mãe/filho, sugerindo considerar os aspectos psíquicos desse exame para a gestante e também para a relação pais-bebêê.

Destaca-se ainda, a proposição da criação de políticas públicas voltadas à gestação e durante o primeiro ano de vida do bebê, objetivando propiciar uma estruturação psíquica de qualidade aos pais e também as crianças ${ }^{29}$. 0 estudo mostra que crianças com pais que não estão suficientemente equilibrados ou com poucas condições emocionais não conseguem promover um desenvolvimento emocional saudável para os seus filhos. Ressalta a "importante vinculação entre 0 desenvolvimento emocional de uma criança, e as circunstâncias em que se dá, tanto a gestação como os primeiros anos de vida" 29:111. Indica ainda que quando os cuidados maternos são sentidos como insuficientes pela criança, o nascimento de mais um irmão, por exemplo, pode causar prejuízos no desenvolvimento psíquico desta criança e promover dificuldades pelo resto de sua vida.

No que tange ao aspecto da relação entre a mãe e seu bebê, uma pesquisa ${ }^{30}$, com objetivo de verificar a qualidade das trocas entre mães-adolescentes e seus filhos lactentes, observou que as mães adolescentes melhor preparadas para a maternidade apresentavam maior sensibilidade em relação aos seus bebês e também eram as que possuíam os filhos mais cooperadores. Ao contrário, quanto menos preparadas, mais comportamentos difíceis tinham os seus filhos aos quatro meses de idade.

Esta pesquisa também revela a relação entre ter sido abusada emocionalmente e o comportamento em relação aos seus filhos. Como resultado, aponta o grupo de mães que apresentavam comportamentos indiferentes em relação aos bebês serem maior no grupo de mulheres emocionalmente abusadas do que no grupo de mães que não foram abusadas.

Os problemas de ordem emocional em mulheres durante o período gestacional relacionam-se tanto em relação às consequências na saúde da mãe, quanto no desenvolvimento infantil e na relação que irá se estabelecer entre a mãe e o seu bebê.

A participação de uma equipe multiprofissional no grupo de gestantes poderia prevenir além de tratar alterações emocionais durante o pré-natal, relatando uma diminuição com diferença estatisticamente significante, entre antes e após a participação da gestante nos grupos psicoprofiláticos ${ }^{31}$. Estes grupos incluíam técnicas de relaxamento, automassagem, massagem do bebê, cantigas de ninar, dinâmicas para trabalhar os sentimentos, as ansiedades e as dúvidas. Outro tema desenvolvido no grupo foi a relação entre mãe e concepto e a importância da função paterna.

Em relação a grupos ${ }^{32}$, foi avaliado que gestantes e acompanhantes relataram que a participação no grupo contribuiu para desvendar crenças e mitos, aumentar o conhecimento sobre a participação do companheiro nesta nova fase, as transformações durante a gravidez, os cuidados consigo e também com o bebê. Este estudo também revela que a preocupação

Saúde (Santa Maria), v.38, n.1, p. 31-46, 2012 Wazlawik, M. R. F.; Sarturi, F. ISSN 2236-5843 
quanto à maternidade e paternidade não parece centralizar a atenção da gestante devido à ansiedade em relação ao parto. Sugere-se que se estabeleçam formas criativas para estimular a atenção da gestante e seu acompanhante para os cuidados com o bebê e com ela mesma, além de melhorar as condições dos participantes para exercerem a maternidade e a paternidade.

Em outro projeto realizado com gestantes ${ }^{33}$, experiência dentro do Projeto MãeCriadeira, voltada à compreensão dos efeitos da discriminação e intolerância racial e a relação com a saúde mental de gestantes, idealizado para fins terapêuticos de prevenção, visando além da saúde física, a saúde emocional da mãe e seu bebê.

Como exemplo de rede de sustentação, proporcionando as gestantes a valorização de seu mundo interno, a terem mais confiança em si, mais criatividade, mais compreensão de seus direitos e deveres, além de estimular e melhorar os cuidados para com o bebê e também para com a família. Esta intervenção consistia em encontros grupais constituído de palestras informativas com vivências grupais ${ }^{33}$. Após cada palestra, acontecia uma vivência coordenada por um facilitador, com o objetivo da construção dessa vivência, e intermediar as repercussões subjetivas surgidas com 0 conteúdo apresentado, além de permitir também a rememoração de conteúdos vividos anteriormente. Assim, era possibilitado pelo facilitador a elaboração e o escoamento da tensão psíquica que o novo assunto suscitava, além de encontrar uma forma adequada de existir simultaneamente com as fantasias decorrentes de medos, mitos, crenças e ansiedades em relação à gravidez, ao parto e aos cuidados com 0 bebê.

Neste tipo de intervenção, compreende-se que a abordagem com profissionais habilitados possibilita além do alívio das tensões, a valorização de si e principalmente a reconfiguração de questões subjetivas que possam estar equivocadas, ou mesmo, aquelas questões que precisam ser resignificadas.

\section{Considerações finais}

Após a sistematização das informações obtidas com esta pesquisa, observam-se problemas de ordem emocional, como os relacionados à autoestima, depressão, ansiedade e uso de tabaco e álcool e estudos que assinalam a importância da atenção no pré-natal incluir o acompanhamento emocional e psicológico e de promover a saúde não só da gestante, mas também desta relação mãe-bebê durante a gestação.

As intervenções em saúde mental, na grande maioria, ficam restritas em possibilitar às gestantes, a expressão de sentimentos, medos e dúvidas e no acolhimento e escuta desta demanda. Verifica-se também uma escassez de orientações relacionadas aos aspectos psíquicos envolvidos na estruturação do bebê e da falta de padronização no atendimento em saúde mental da gestante.

Os profissionais envolvidos nas orientações e que tentam dar conta destas questões psíquicas são na maioria da área médica e de enfermagem, tendo este último uma predominância maior. 0 envolvimento de outros profissionais como psicólogos, geralmente fica restrito a participação das gestantes em grupos. Ressalta-se ainda a pouca participação de gestantes nos grupos e que gestantes com baixa autoestima, depressivas, usuárias de álcool e usuárias de drogas resistem mais a participar de atividades grupais. 
Para que isso se modifique, acredita-se que seja necessário primeiramente dar maior atenção aos aspectos de ordem emocional, pois foi possível perceber neste estudo, os transtornos psíquicos, além de serem mais comuns do que se pensa, determinam uma grande quantidade de mães fragilizadas e as consequências disto na relação mãe/bebê e também no desenvolvimento infantil.

As políticas de saúde da mulher, especificamente no pré-natal, deveriam ser aprimoradas, dando maior relevância aos aspectos de saúde mental das gestantes, capazes de propiciar qualidade nos aspectos psíquicos e consequentemente na estruturação psíquica das crianças.

\section{Referências}

1. Malta DC, Merhy EE. O Percurso da linha do cuidado sob a perspectiva das doenças crônicas não transmissíveis. Interface - Comunic, Saude Educ. 2010; 14(34): 506-93.

2. Santos Neto ET, Alves KCG, Zorzal M, Lima RCD. Políticas de Saúde Materna no Brasil: os nexos com indicadores de saúde materno-infantil. Saúde Soc. 2008; 17(2): 107-19.

3. Minayo MCS. O Desafio do Conhecimento: Pesquisa Qualitativa em Saúde. 8ª ed. São Paulo: Hucitec. 2004.

4. Silva RA, Ores LC, Mondin TC et al. Transtornos mentais comuns e auto-estima na gestação: prevalência e fatores associados. Cad. Saúde Pública. 2010: 26(9), 1832-8.

5. Maçola L, Vale IN, Carmona EV. Avaliação da autoestima de gestantes com uso da Escala de Autoestima de Rosemberg. Rev. Esc. Enferm. USP. 2010;44(3): 570-7.

6. Dias MS, Silva RA, Souza LDM, Lima RC, Pinheiro RT, Moraes IGSI. Auto-estima e fatores associados em gestantes da cidade de Pelotas, Rio Grande do Sul, Brasil. Cad. saúde pública, 2008; 24(12): 2787- 97.

7. Pereira PK, Lovisi GM, Lima LA, Legay LFL. Complicações obstétricas, eventos estressantes, violência e depressão durante a gravidez em adolescentes atendidas em unidade básica de saúde. Rev Psiquiatr Clín. 2010; 37(5): 216-22.

8. Caputo VG, Bordin IA. Problemas de saúde mental entre jovens grávidas e não-grávidas. Rev Saúde Pública. 2007; 41(4): 573-81.

9. Araújo DMR, Pacheco AHRN, Pimenta AM, Kac G. Prevalência e fatores associados a sintomas de ansiedade em uma coorte de gestantes atendidas em um centro de saúde do município do Rio de Janeiro. Rev Bras Saúde Mater Infant. 2008; 8(3): 333-40.

10. Fonseca VRJRM, Silva GA, Otta E. Relação entre depressão pós-parto e disponibilidade emocional materna. Cad saúde pública. 2010; 26(4): 738-46.

11. Schimidt EB, Argimon II. Vinculação da gestante e apego materno fetal. Paidéia. 2009; 19(43): 211-20.

12. Pinheiro SN, Lapregna MR, Furtado EF. Morbidade psiquiátrica e uso de álcool em gestantes usuárias do Sistema Único de Saúde. Rev saúde pública. 2005; 39(4): 593-8.

13. Moraes $\mathrm{CL}$, Reichenheim ME. Rastreamento de uso de álcool por gestantes de serviços públicos de saúde do Rio de Janeiro. Rev Saúde Pública. 2007; 41(5): 695-703.

14. Silva CS, Ronzani TM, Furtado EF, Aliane PP, Moreira-Almeida A. Relação entre prática religiosa, uso de álcool e transtornos psiquiátricos em gestantes. Rev Psiquiatr Clín. 2010; 37(4): 159-63.

15. Oliveira RT, Simões SMF. O consumo de bebida alcoólica pelas gestantes: um estudo exploratório. Esc.

Saúde (Santa Maria), v.38, n.1, p. 31-46, 2012 Wazlawik, M. R. F.; Sarturi, F. Anna Nery Rev de Enferm. 2007; 11(4): 632-8. 
16. Freire K, Padilha PC, Saunders C. Fatores associados ao uso de álcool e cigarro na gestação. Rev Bras Ginecol Obstet. 2009; 31(7): 335-41.

17. Granato TMM, Aiello-Vaisberg TMJ. Maternidade e colapso: consultas terapêuticas na gestação e pósparto. Paidéia; 2009: 395-401.

18. Shimizu HH, Lima MG. As dimensões do cuidado pré-natal na consulta de enfermagem. Rev Bras Enferm. 2009; 62(3): 387-92.

19. Melo JM, Brandão EHS, Dutra SMV, Iwazawa AT, Albuquerque RS. Conhecendo a captação de informações de mães sobre os cuidados com o bebê na Estratégia Saúde da Família. Texto contexto Enferm. 2007; 16(2): 280-6.

20. Rocha DCS, Bezerra MGA, Campos ACSGA. Cuidados com os bebês: o conhecimento das primíparas adolescentes. Esc. Anna Nery Rev de Enferm. 2005; 9(3): 365-71.

21. Duarte SJH, Andrade SMO. Assistência Pré-natal no Programa Saúde da Família. Esc Anna Nery. 2006; 10(1): 121-5.

22. Zampieri MFM, Alacoque LE. Cuidado humanizado no pré-natal: um olhar para além das divergências e convergências. Rev Bras Saúde Mater Infant. 2010; 10(3): 359-67.

23. Reberte LM, Hoga LAK. O desenvolvimento de um grupo de gestantes com a utilização da abordagem corporal. Texto contexto Enferm. 2005; 14(2): 186-92.

24. Hoga LAK, Reberte LM. Técnicas corporais em grupo de gestantes: a experiência dos participantes. Rev Bras Enferm. 2006; 59(3): 308-13.

25. Piccinini CA, Gomes AG, De Nardi T. Lopes RS. Gestação e Constituição da maternidade. Psicol Estud. 2008; 13(1): 63-72.

26. Ferrari AG, Piccinini CA, Lopes RS. O bebê imaginado na gestação: aspectos teóricos e empíricos. Psicol Estud. 2007; 12(2) 305-13.

27. Gomes AG, Piccinini CA. A. Impressões e sentimentos de gestantes em relação à ultra-sonografia obstétrica no contexto de normalidade fetal. Psicol Reflex Crit. 2007; 20(2): 179-87.

28. Gomes AG, Piccinini CA. A ultra-sonografia obstétrica e a relação materno-fetal em situações de normalidade e anormalidade fetal. Est Psicol. 2005; 22(4): 381-93.

29. Maciel RA, Rosemburg CP. A relação mãe-bebê e a estruturação da personalidade. Saúde Soc. 2006; 15(2): 96-112.

30 Bigras M, Paquette D. Estudo pessoa-processo-contexto da qualidade das interações entre mãeadolescente e seu bebê. Ciênc saúde coletiva. 2007; 12(5): 1167-74.

31. Falcone VM, Custódia VNM, Nascimento CFL, Santos JMM, Nóbrega FJ. Atuação multiprofissional e a saúde mental de gestantes. Rev Saúde Pública. 2005; 39(4): 612-8.

32. Zampieri MFM, Gregório VRP, Custódio ZAO, Regis MI, Brasil C. Processo educativo com gestantes e casais grávidos: possibilidade para transformação e reflexão da realidade. Texto contexto - enferm. 2010; 19(4): 719-27.

33. Guimarães MAC, Podkameni AB. A rede de sustentação coletiva, espaço potencial e resgate identitário: projeto mãe-criadeira. Saúde Soc. 2008; 17(1): 117-30.

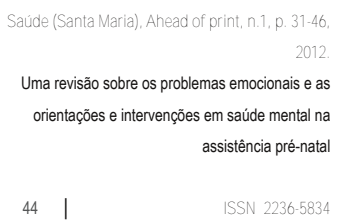




\section{Márcia Rosana Forster Wazlawik}

Endereço para correspondência - Rua Ernesto Alves, 858, Bairro centro. Santa Cruz do Sul, RS. 96810-060

E-mail: marciawazlawik@yahoo.com.br

Currículo Lattes: http://lattes.cnpq.br/2122599222243890

Recebido em 14 de outubro de 2011.

Aprovado em 11 de junho de 2012 
Uma revisão sobre os problemas emocionais e as orientaçōes e intervençōes em saúde mental na assistência pré-natal 